\title{
A Demanda por Energia Elétrica no Brasil*
}

\author{
Cristiane Alkmin Junqueira Schmidt ${ }^{* *}$ \\ Marcos A. M. Lima ${ }^{* *}$
}

Sumário: 1. Introdução; 2. Resenha sobre o estudo das elasticidades e o modelo teórico adotado; 3. Metodologia e dados; 4. Estimação das funções de demanda e comparações dos resultados com os de outros estudos; 5 . Previsões para os consumos de energia elétrica; 6. Conclusão.

Palavras-chave: energia elétrica; elasticidade; cointegração.

Código JEL: Q41.

O objetivo do presente trabalho é estimar, por cointegração, as elasticidades, preço e renda, de longo prazo da demanda por energia elétrica nas três classes de consumo: residencial, comercial e industrial. Os resultados obtidos estão de acordo com outros resultados empíricos de que a elasticidade-renda deve ser igual ou superior à unidade e que a elasticidade-preço deve ter uma magnitude inferior a um, em módulo. Além disso são realizadas previsões para o consumo de energia elétrica para o período de 2001 a 2005.

The purpose of the present study is to estimate, by cointegration, the long-run elasticities, mainly the price and income, of the demand for electric energy in the three consumption categories: residential, commercial and industrial. The obtained results support the premise that the income elasticity should be near or beyond a unity, and that the magnitude of price-elasticity should be lower one, in terms of absolute value. Predictions for the electric energy consumption for the 2001-2005 period are also made.

\section{Introdução}

Com a privatização da infra-estrutura iniciada na década de 90 , o setor de energia elétrica, fundamental para o desenvolvimento da economia e que apresenta características de monopólio natural em alguns dos seus segmentos (transmissão e

*Artigo recebido em fev. 2002 e aprovado em mai. 2003. Os autores agradecem a colaboração de Isabel Ramos Sousa.

${ }^{* *}$ Mestre e doutoranda - EPGE/FGV e Secretária-Adjunta da SEAE do Ministério da Fazenda. E-mail: schmidt@prtc.net

*** IBMEC-RJ. E-mail: maml@gbl.com.br 
distribuição), ${ }^{1}$ posicionou-se como um dos grandes precursores deste processo de reforma do Estado. ${ }^{2}$ Este fato contribuiu para estimular os investimentos neste setor. Em 1994, a capacidade instalada nacional era aproximadamente de $54 \mathrm{GW}$, em 2001, de 80 GW (incluindo importações de Itaipu e demais) e deve atingir 104 GW em $2004 .^{3}$

Além disso, apesar de parte considerável deste investimento ter sido realizada para cobrir investimentos não realizados no passado, ${ }^{4}$ o futuro do setor parece ter boas perspectivas no que diz respeito ao seu crescimento. Segundo dados do Ministério de Minas e Energia, 20 milhões de brasileiros no meio rural ainda não têm acesso à energia elétrica. ${ }^{5}$ Adicionalmente a existência desta demanda reprimida houve, de junho de 2001 a fevereiro de 2002, racionamento de energia elétrica em todo o país, ${ }^{6}$ mostrando que o setor ainda carece de investimentos, principalmente nos segmentos de geração e transmissão. Nota-se, portanto, que mesmo em 2002, a preocupação em expandir e modernizar o setor ainda persiste.

O objetivo deste artigo é estimar os parâmetros da função de demanda (elasticidades-preço e renda) por energia elétrica no Brasil para as três classes: residencial, comercial e industrial e fazer previsões do consumo para os próximos cinco anos. Estes dados são relevantes não só para uma melhor otimização do planejamento energético, mas também para auxiliar o órgão regulador nas formulações de regras para este setor.

O artigo está dividido em 6 seções. Na seção 2, está exposta uma resenha referente a estudos sobre elasticidades e ao modelo teórico adotado. Na seção 3, aborda-se sobre os dados e a metodologia. Na seção 4, são apresentadas as estimações e comparações dos resultados obtidos neste artigo com os de outros estudos. Na seção 5, são expostas as previsões para o consumo de energia elétrica para o período entre 2001/2005. E para finalizar, na seção 6, apresenta-se a conclusão do artigo.

\footnotetext{
${ }^{1}$ Nogueira (1996), Rigolon (1996) e Lizardo (1996).

${ }^{2}$ Leite (1997)

${ }^{3}$ Ministério de Minas e Energia e www.energiabrasil.gov.br.

${ }^{4}$ Almeida (1983).

${ }^{5}$ Jornal O Estado de São Paulo, 14/02/99.

${ }^{6}$ Regiões Sudeste/Centro-Oeste/Nordeste: de 01/06/01 a 28/02/02 e Região Norte: de 15/08/01 a 01/01/02. Fonte: www.energiabrasil.gov.br.
} 


\section{Resenha sobre o Estudo das Elasticidades e o Modelo Teórico Adotado}

\subsection{Uma resenha da literatura}

Outros estudos foram realizados sobre este mesmo tema, inclusive para o Brasil, o que torna este trabalho uma atualização com relação ao caso brasileiro - com uma ampliação para outros tipos de consumidores de energia elétrica, utilização de um conjunto maior de informação e metodologias econométricas mais modernas.

Modiano (1984) estimou as demandas para o Brasil, para as três classes, no período de 1963 a 1981, a partir de dados anuais. Ele concluiu que, para as classes residencial, comercial e industrial, as elasticidades-preço de curto prazo eram, respectivamente, $-0,118,-0,062$ e $-0,451$; as elasticidades-preço de longo prazo eram $-0,403,-0,183$ e $-0,222$; as elasticidades-renda de curto prazo eram $0,332,0,362$ e 0,502 e as elasticidades-renda de longo prazo eram 1,13, 1,068 e 1,360 .

Já Andrade e Lobão (1997) estimaram a demanda para o caso residencial no Brasil, no período de 1963 a 1995, a partir de dados anuais. Eles chegaram a conclusão de que as elasticidades-preço de curto e longo prazos eram $-0,06$ e $-0,051$; e as elasticidades-renda de curto e longo prazos eram 0,212 e 0,213.

Comparando os dois trabalhos acima mencionados, para o caso residencial, a diferença qualitativa entre os resultados está na elasticidade-renda de longo prazo. No trabalho de Modiano, este parâmetro era rejeitado caso fosse igual a um (hipótese nula), contrapondo-se à hipótese de que era maior do que 1 (hipótese alternativa). Em contrapartida, no trabalho de Andrade e Lobão, esta elasticidade ficou em um patamar próximo a 0,2, bem inferior ao encontrado em Modiano.

No trabalho realizado por Bentzen e Engsted (1993), as estimações foram realizadas para a demanda total de energia para a Dinamarca no período compreendido entre 1948 e 1990, a partir de dados anuais. Os resultados foram os seguintes: as elasticidades-preço de curto e longo prazos foram, respectivamente, -0, 135 e $-0,465$, enquanto as elasticidades-renda de curto e longo prazos foram, respectivamente, 0,666 e 1,213 .

Já no trabalho realizado por Houthakker (1951), em que as estimações sobre a demanda total de energia elétrica foram realizadas para 42 províncias na GrãBretanha no período de 1937 a 1988, as elasticidades-preço e renda de longo prazo foram, respectivamente, $-0,8928$ e 1,166.

Repare, portanto, que a elasticidade-renda de longo prazo destes dois últimos trabalhos mencionados acima assemelham-se mais com aquelas encontradas em 
Modiano do que com as estimadas por Andrade e Lobão.

Dois trabalhos, neste mesmo assunto, foram realizados, também, por Westley $(1984,1989)$. Em ambos os trabalhos foram estimadas as elasticidades-preço e renda de longo prazo, sendo o primeiro para o Paraguai e o segundo para a Costa Rica. Para o primeiro país, as elasticidades-preço e renda foram, respectivamente, $-0,56$ e 0,42 ; e para o segundo país, foram $-0,5$ e 0,5 , respectivamente. Além disso, ele rejeita a hipótese de que a elasticidade-renda seja igual a 1, contrapondose a hipótese de que a mesma seja menor do que 1.

Observe que estes resultados, concentrando-se no caso da elasticidade-renda, se assemelham mais à pesquisa de Andrade e Lobão. No entanto, ainda aqui, vale mencionar um comentário de Westley (1989) sobre as elasticidades- preço e renda encontradas em seu estudo: ${ }^{7}$ "estes valores contradizem a noção que alguns planejadores da América Latina têm sobre a energia elétrica, qual seja, a que o consumo de energia elétrica cresce em proporção fixa com a renda e tem elasticidade preço perto de zero". A contradição a que ele se refere é relativa ao resultado da elasticidade-renda por ele encontrada, pois era de se esperar que a mesma deveria não rejeitar a hipótese de que a elasticidade renda fosse pelo menos igual a um.

Entre outros trabalhos nesta área, pode-se citar também, outros seis. Silk e Joutz (1997), Wills (1981), Smith (1980) e Donatos e Mergos (1991) estimaram a demanda de energia elétrica para o caso residencial. Os três primeiros para os Estados Unidos e o último para a Grécia. As elasticidades preço e renda, respectivamente, para Silk e Joutz foram -0, 48 e 0,52 (longo prazo) no período entre 1949 e 1993, e para Smith ficaram nos intervalos entre $-0,18$ e -1 e 0,66 e 1,53 (curto prazo), no período entre 1957 e 1972. Já para Wills, a elasticidade preço de longo prazo foi -0, 25 em 1975. Ele fez um cross section entre vinte e sete distritos de Massachusetts e não estimou a elasticidade renda. Donatos estimou tanto para o curto quanto para o longo prazo no período entre 1961 e 1986 . Seus resultados foram: para o curto prazo, $-0,21$ e 0,53 e para o longo prazo, $-0,58$ e 1,5. Beenstock et alii (1999) estimaram as elasticidades preço de longo prazo para Israel, entre 1965 e 1995, para os casos industrial e residencial. No primeiro caso o resultado foi $-0,435$ e no segundo, -0,579. Já Christopoulos (2000) estimou a demanda por energia industrial (diesel, eletricidade e petróleo) para a Grécia entre 1970 e 1990 e a elasticidade preço foi -0,11.

Portanto, analisando os resultados encontrados, conclui-se que, de forma geral: as elasticidades-preço de curto prazo (em valores absolutos) são menores ou iguais

\footnotetext{
${ }^{7}$ Tradução Livre.
} 
às elasticidades-preço de longo prazo $;^{8}$ o módulo das elasticidades-preço se encontra no intervalo $[0 ; 0,5], 3)$ as elasticidades-renda de curto prazo são menores ou iguais às elasticidades-renda de longo prazo; as elasticidades-renda de curto prazo oscilam dentro do intervalo $[0,2 ; 0,7]$ e as elasticidades-renda de longo prazo não mostram resultados homogêneos entre os trabalhos. Em algumas pesquisas seu valor oscila entre $[0,2 ; 0,5]$ e em outros, seu valor pertence ao intervalo $[1 ; 1,3]$.

\subsection{Modelo teórico}

A demanda residencial por energia elétrica pode ser descrita, à princípio, como um resultado de um problema de maximização de utilidade, sujeita a uma restrição orçamentária. Já as demandas comercial e industrial podem ser melhor descritas como um problema de minimização de custo, sujeito a um certo nível de produção. ${ }^{9}$ Contudo, como a demanda por eletricidade, seja para qualquer das três classes mencionadas, é derivada da necessidade do indivíduo ou da firma fazer um determinado aparelho elétrico ou uma determinada máquina funcionar, a energia pode ser melhor interpretada como um fator que participa de processos ou atividades produtoras de bens. Desta forma, mesmo para o caso residencial, o modelo que melhor descreve o problema é o segundo mencionado.

Assim, seja a seguinte "função de demanda derivada" por energia elétrica: ${ }^{10}$ $C_{t}=k P_{t}^{\alpha} Y_{t}^{\beta} L_{t}^{\delta} S_{t}^{\phi}, k>0, \alpha<0, \beta>0, \delta<0, \phi>0$, que tomando o seu logaritmo, chega-se à seguinte equação linear de demanda por energia elétrica:

$$
\log C_{t}=\log k+\alpha \log P_{t}+\beta \log Y_{t}+\delta \log L_{t}+\phi \log S_{t}
$$

onde:

$C_{t}$ é o consumo (residencial, comercial ou industrial) de energia elétrica no tempo $t$

$P_{t}$ é a tarifa (residencial, comercial ou industrial) de energia elétrica no tempo $t$;

$Y_{t}$ é a renda (rendimento do trabalhador, no caso residencial, e PIB nos casos comercial e industrial) no tempo $t$;

$L_{t}$ é o preço dos aparelhos eletrodomésticos (residencial) ou eletrointensivos (ligados ao comércio ou à indústria) no tempo $t$;

\footnotetext{
${ }^{8}$ Fato também observado por Berndt (1991). Segundo este autor, a ineslaticidade do curto prazo, vis-à-vis a de longo prazo, pode ser explicada pelo fato dos estoques de equipamentos eletrointensivos serem mais facilmente trocados no longo prazo.

${ }^{9}$ Mas-Colell et alii (1995), Becker (1971) e Holanda (1985).

${ }^{10} \mathrm{~A}$ função de demanda Cobb Douglas foi utilizada tanto por Andrade e Lobão (1997) quanto por Modiano (1984).
} 
$S_{t}$ é o preço de um bem substituto à energia elétrica no tempo $t$ (o único segmento que tem um possível bem substituto à energia elétrica é o industrial);

$\xi_{p}=\alpha$ é a elasticidade-preço, $\xi_{r}=\beta$ é a elasticidade-renda e $\xi_{l}=\delta$ é a elasticidadepreço do estoque dos aparelhos eletrodomésticos/eletrointensivos, $\xi_{l}=\phi$ é a elasticidade-preço do bem substituto e $k$ é uma constante.

\section{Metodologia e Dados}

\subsection{Metodologia}

Existem ao menos duas metodologias possíveis para estimar uma função de demanda: pelo modelo de equações simultâneas ou por cointegração.

A segunda metodologia, que segue o modelo de Johansen $(1988,1991)$ e ainda Johansen e Juselius (1990), propõe a utilização de um modelo VAR, isto é, uma modelagem de vetores auto-regressivos (VAR), para estimar os vetores de cointegração. No presente trabalho será estimado o vetor de cointegração relativo ao consumo de energia elétrica e os parâmetros deste vetor representarão as elasticidades de longo prazo. Ainda será feita uma previsão para o consumo de energia elétrica. Para tanto, o VAR será representado, segundo Engle e Granger (1987), na forma de um Modelo de Correção de Erro Vetorial (MCEV).

Este tipo de modelagem (VAR - MCEV) parece ser mais interessante para este trabalho, e por isso foi adotada, pois, por levar em consideração as variáveis e suas defasagens, concilia as tendências de curto e longo prazos das variáveis do modelo. Além disso, este enfoque oferece flexibilidade suficiente para obter uma boa representação estatística dos dados, sem a necessidade de introduzir variáveis $a d-h o c$ a priori, caso fosse a solução para identificar uma ou mais equações no modelo de equações simultâneas.

\subsection{Dados}

Os dados para a estimação da demanda por energia elétrica poderiam, a princípio, ter três periodicidades distintas. Os dados poderiam ser mensais, anuais ou trimestrais. Os dados trimestrais não foram utilizados, pois não haviam dados referentes às tarifas de energia elétrica por classes de consumo e referentes aos preços dos bens substitutos. Os dados mensais, por outro lado, estavam disponíveis a partir de 1990 e os anuais, a partir de 1969. Assim, a escolha da série poderia ter sido tanto mensal como anual. Como os outros trabalhos que 
estimaram as elasticidades para o Brasil apresentaram séries anuais, desde 1969, optou-se pela escolha da série anual.

Abaixo, na tabela 1, pode-se encontrar um resumo dos dados e das fontes utilizados no trabalho.

Tabela 1

Fonte e dados utilizados

\begin{tabular}{|c|c|c|}
\hline & Variável (séries anuais de 1969 a 1999) & Fonte \\
\hline \multicolumn{3}{|c|}{ Caso Residencial } \\
\hline $\mathrm{P}$ & Tarifa Média Residencial em Valores Constantes & Eletrobrás \\
\hline & de 1999 & Deflator IGP-DI (FGV) \\
\hline $\mathrm{L}$ & $\begin{array}{l}\text { IPA-DI - Bens de Consumo Duráveis - Utilidade } \\
\text { Base: ano de } 1999=100\end{array}$ & $\begin{array}{l}\text { Banco de dados Aries/IBRE/FGV/RJ } \\
\text { Deflator IPA-DI }\end{array}$ \\
\hline Y & $\begin{array}{l}\text { Rendimento Médio Real dos Assalariados }- \\
\text { Trabalho principal. Base: ano de } 1999=100\end{array}$ & IBGE- Contas Nacionais in Ipeadata \\
\hline $\mathrm{C}$ & Consumo Total Residencial (MWh) & Eletrobrás \\
\hline \multicolumn{3}{|c|}{ Caso Comercial } \\
\hline $\mathrm{P}$ & $\begin{array}{l}\text { Tarifa Média Comercial em Valores Constantes } \\
\text { de } 1999\end{array}$ & $\begin{array}{l}\text { Eletrobrás } \\
\text { Deflator IGP-DI }\end{array}$ \\
\hline $\mathrm{L}$ & $\begin{array}{l}\text { IPA-OG - Mat. Elétrico. } \\
\text { Base: ano de } 1999=100\end{array}$ & $\begin{array}{l}\text { Banco de dados Aries/IBRE/FGV/RJ } \\
\text { Deflator IPA-DI }\end{array}$ \\
\hline $\mathrm{Y}$ & PIBpm - Preços Constantes de 1999 & $\begin{array}{l}\text { FGV/RJ } \\
\text { Deflator implícito do PIB }\end{array}$ \\
\hline $\mathrm{C}$ & Consumo Total Comercial (MWh) & Eletrobrás \\
\hline \multicolumn{3}{|c|}{ Caso Industrial } \\
\hline $\mathrm{P}$ & $\begin{array}{l}\text { Tarifa Média Industrial em Valores Constantes } \\
\text { de } 1999\end{array}$ & $\begin{array}{l}\text { Eletrobrás } \\
\text { Deflator IGP-DI }\end{array}$ \\
\hline $\mathrm{S}$ & $\begin{array}{l}\text { IPA-OG - Combustível e Lubrificantes. } \\
\text { Base: ano de } 1999=100\end{array}$ & $\begin{array}{l}\text { Banco de dados Aries/IBRE/FGV/RJ } \\
\text { Deflator IPA-DI }\end{array}$ \\
\hline $\mathrm{L}$ & $\begin{array}{l}\text { IPA-OG- Máquinas e Equipamentos Industriais. } \\
\text { Base: ano de } 1999=100\end{array}$ & $\begin{array}{l}\text { Banco de dados Aries/IBRE/FGV/RJ } \\
\text { Deflator IPA-DI }\end{array}$ \\
\hline Y & PIBpm - Preços Constantes de 1999 & $\begin{array}{l}\text { FGV/RJ } \\
\text { Deflator implícito do PIB }\end{array}$ \\
\hline $\mathrm{C}$ & Consumo Total Industrial (MWh) & Eletrobrás \\
\hline
\end{tabular}

\section{Consumo de Energia Elétrica}

O consumo total de energia elétrica passou de 18.346 GWh em 1960 para 304.634 GWh em 2000, o que representa uma taxa de crescimento média anual no período de $7,35 \%$. Na década de 60 o crescimento residencial foi de $8,22 \%$, o comercial de $7,81 \%$ e o industrial de $7,06 \%$. Já na década de 70 , o setor industrial teve maior expansão, com um crescimento médio anual de 13,62\%. O residencial ficou em seguida, com 10,49\% e o comercial com 10,17\%. Mesmo nos anos 80, na chamada década perdida, houve um crescimento razoável das três classes, sendo o residencial o maior contribuinte com $7,62 \%$, enquanto as demais classes ficaram em patamares de $5,96 \%$ o comercial e $5,76 \%$ o industrial. 
Foi na década de 90 que, enquanto as taxas médias anuais de crescimento referentes a este período para as classes residencial e comercial ficaram em patamares de $5,94 \%$ e $6,95 \%$ respectivamente, a industrial ficou em $1,94 \%$.

Os anos que mais contribuíram para estes números (casos residencial e comercial) foram os que vieram logo após a implementação do Plano Real, isto é, nos anos 1995 e 1996. Neste último ano, por exemplo, o crescimento residencial foi de $8,70 \%$, o comercial de $8,16 \%$ e o industrial de $-1,23 \%$.

Em 1960 a participação do consumo dos setores residencial, comercial e industrial era de $21,09 \%, 14,29 \%$ e $50,01 \%$, e passou em 2000 para $26,88 \%, 15,35 \%$ e $43,30 \%$, mostrando que o setor residencial foi o que mostrou maior dinamismo na participação do crescimento do consumo total e o industrial o menor entre os três.

\section{Produto Interno Bruto (PIB)}

O PIB em 1960 era de $\mathrm{R} \$ 152.269$ milhões e em 2000 passou para $\mathrm{R} \$ 1.153 .080$ milhões, ambos a preços constantes de 2000. O crescimento médio anual referente ao período de 1960 a 2000 foi de $5,30 \%$, o que equivale a uma variação no período de $657 \%$. Nas décadas de $60,70,80$ e 90, este crescimento médio anual foi de, respectivamente, $5,80 \%, 8,93 \%, 3,78 \%$ e $2,96 \%$.

\section{Tarifas de Energia Elétrica}

As tarifas de energia elétrica, de um modo geral, tiveram aumento real na década de 70, principalmente entre os anos 1971 e 1974, e a partir de então passaram a ter perda real progressiva, até os anos 90, quando deram um leve salto, mantendo-se um pouco acima dos valores, em termos reais, de 1963.

Nos casos residencial, comercial e industrial, os anos que apresentaram maior nível de preços foram; respectivamente a cada classe; 1972, 1972 e 1965, com os valores de 338,73; 332,21 e 128,50. Já aqueles de menor nível foram os anos 1986, 1985 e 1985, com valores de 78,92; 119,53 e 64,55. As variações percentuais entre as datas de "pico" e "vale" de cada classe foram de: $-76,70 \%,-64,02 \%$ e $-49,77 \%$, respectivamente.

As tarifas que apresentaram maior variabilidade foram aquelas relativas à classe residencial, seguida pela classe comercial. Se for comparado o nível de preços entre 1963 e 1969, as tarifas residencial, comercial e industrial cresceram, respectivamente, $92,44 \%, 88,99 \%$ e 58,69\%. Se a comparação for feita entre 1970 e 1979, a tarifa residencial decaiu $20,84 \%$, a comercial $21,13 \%$ e a industrial $17,27 \%$. Já na 
década de 80, entre os anos de 1980 e 1989, as tarifas residencial, comercial e industrial decaíram $42,46 \%, 20,68 \%$ e 13,47\%, respectivamente, indicando a persistência da queda real das tarifas no setor.

Já no período compreendido entre 1990 e 2000, houve um aumento real da tarifa no segmento residencial, 14,69\%, e uma leve queda nos demais segmentos, $-22,78 \%$ (comercial) e $-21,61 \%$ (industrial).

\section{Estimação das Funções de Demanda e Comparações dos Re- sultados com os de outros Estudos}

\subsection{Residencial}

Para a estimação da demanda foi aplicado logaritmo natural aos valores observados das séries com a finalidade de obter as elasticidades da demanda por energia elétrica, como parâmetros da equação estimada.

Antes de realizar a análise de cointegração entre as diferentes séries utilizadas, verificou-se a estacionariedade destas séries. Para isso, utilizou-se o teste de raiz unitária de Dickey-Fuller Aumentado - ADF $(1979,1981) .{ }^{11}$

Esta necessidade decorre do fato da análise de cointegração, geralmente, só ser válida para séries não-estacionárias e que possuam a mesma ordem de integração. ${ }^{12}$ Em geral, as séries econômicas são estacionárias em primeira diferença, tendo, portanto, ordem de integração igual a um.

Assim, foram realizados os testes de raiz unitária (ADF) em todas as quatro séries, e os resultados estão apresentados na tabela 2 a seguir:

Tabela 2

Testes de raiz unitária (ADF)

\begin{tabular}{l|l|c|c|c|c}
\hline Variável & Termos da equação & Número de & Estatística de & \multicolumn{2}{|c}{ Valor Crítico } \\
\cline { 4 - 6 }$(\mathrm{em} \mathrm{log})$ & & defasagens & teste $(\mathrm{ADF})$ & $5 \%$ & $1 \%$ \\
\hline$C_{t}$ & Constante & 0 & $-3,015$ & $-2,9627$ & $-3,666$ \\
$P_{t}$ & Constante & 0 & $-1,179$ & $-2,9627$ & $-3,666$ \\
$Y_{t}$ & Constante e tendência & 0 & $-2,450$ & $-3,567$ & $-4,295$ \\
$L_{t}$ & Constante e tendência & 0 & $-1,700$ & $-3,567$ & $-4,295$ \\
\hline
\end{tabular}

\footnotetext{
${ }^{11}$ Além do texto original, pode-se encontrar este teste, como todo o procedimento de cointegração, em Hamilton (1994), em Enders (1995) ou em Hendry (1995).

${ }^{12}$ De acordo com Rahbek e Mosconi (1999), mesmo que se tenha N séries não estacionárias de mesma ordem de integração e $M$ séries estacionárias $(M<N)$, os resultados dos testes de cointegração podem não se alterar.
} 
As escolhas do número de defasagens (coluna 3 da tabela 2) e da inclusão ou não de constante e tendência (coluna 2 da tabela 2 ) em cada uma das séries se deu da seguinte forma:

Primeiro definiu-se o número de defasagens. Para tanto, foi feito o teste ADF com um número grande de defasagens ( $\mathrm{N}=6$, por exemplo) e observou-se se a última defasagem era estatisticamente significativa. Caso fosse, o modelo teria $\mathrm{N}$ defasagens, e caso não fosse, repetiria-se o teste com N-1 defasagens e o mesmo procedimento seria realizado até encontrar o número correto de defasagens. Encontrado este número, partiu-se para a inclusão ou não de constante e tendência. Para tanto, estimou-se a equação com o número de defasagens definido anteriormente e com constante e tendência. Se a tendência fosse significativa, a equação conteria uma constante e uma tendência. Se a tendência não fosse significativa, ${ }^{13}$ retiraria-se a tendência e a equação seria estimada novamente para observar se a constante seria significativa. Se fosse, esta ficaria no modelo. Se não fosse, seria retirada.

De acordo com os resultados da tabela 2, verifica-se que não se pode rejeitar que cada uma das séries analisadas seja não-estacionária ao nível de significância de 1\% (isto é, não é possível rejeitar a hipótese nula: há presença de raiz unitária em cada uma das séries). Já ao nível de significância de $5 \%$ a série que representa o logaritmo do consumo é rejeitada.

Adicionalmente foram realizados testes de raiz unitária para as séries em primeira diferença, como pode ser verificado na tabela 3 abaixo:

Tabela 3

Testes de raiz unitária (ADF)

\begin{tabular}{l|l|c|c|c|c}
\hline $\begin{array}{l}\text { Variável } \\
(\mathrm{em} \log )\end{array}$ & Termos da equação & \multirow{2}{*}{$\begin{array}{c}\text { Número de } \\
\text { defasagens }\end{array}$} & $\begin{array}{c}\text { Estatística de } \\
\text { teste }(\mathrm{ADF})\end{array}$ & \multicolumn{2}{|c}{ Valor Crítico } \\
\cline { 3 - 5 } & & 0 & $-3,767$ & $-3,573$ & $-4,308$ \\
$\Delta C_{t}$ & Constante e tendência & 0 & $-5,196$ & $-2,966$ & $-3,675$ \\
$\Delta P_{t}$ & Constante & 0 & -4.475 & $-3,573$ & $-4,308$ \\
$\Delta Y_{t}$ & Constante e tendência & 0 & $-5,316$ & $-3,573$ & $-4,308$ \\
$\Delta L_{t}$ & Constante e tendência & 0 & \\
\hline
\end{tabular}

Observa-se, pela tabela acima, que cada série é estacionária (isto é, rejeita-se a hipótese de raiz unitária em cada uma das séries) aos níveis de significância de $1 \%$ e $5 \%$, com exceção do consumo a $1 \%$. Com isso, a $5 \%$, pode-se concluir que todas as séries possuem a mesma ordem de integração, isto é, são todas $I(1)$. Destarte, é possível que haja relação de cointegração entre estas séries.

\footnotetext{
${ }^{13}$ A tendência é significativa ou não, segundo a tabela em Dickey e Fuller (1981), que pode ser também encontrada em Enders (1995:223).
} 
Assim, parte-se para a verificação da cointegração entre as séries escolhidas, pelo modelo de Johansen, que faz uso de um VAR. Se as séries cointegrarem, podese dizer que há uma relação de longo prazo entre elas e os coeficientes do vetor de cointegração serão as elasticidades de longo prazo da demanda por energia elétrica. Assim, define-se a especificação correta do VAR, na forma padrão, qual seja:

$$
\left[\begin{array}{c}
C_{t} \\
P_{t} \\
Y_{t} \\
L_{t}
\end{array}\right]=\left[\begin{array}{c}
A_{11}(L) A_{12}(L) A_{13}(L) A_{14}(L) \\
A_{21}(L) A_{22}(L) A_{23}(L) A_{24}(L) \\
A_{31}(L) A_{32}(L) A_{33}(L) A_{34}(L) \\
A_{41}(L) A_{45}(L) A_{43}(L) A_{44}(L)
\end{array}\right]\left[\begin{array}{c}
C_{t-1} \\
P_{t-1} \\
Y_{t-1} \\
L_{t-1}
\end{array}\right]+\left[\begin{array}{c}
e_{t}^{C} \\
e_{t}^{P} \\
e_{t}^{Y} \\
e_{t}^{L}
\end{array}\right]
$$

No que concerne ao número de defasagens, ${ }^{14}$ utilizou-se os critérios de informação de Akaike e Schwarz, ${ }^{15}$ como pode ser observado na tabela 4 abaixo.

Tabela 4

Definição do número de defasagens do VAR

\begin{tabular}{ccc}
\hline Defasagens & AIC & SBC \\
\hline 3 & 173.4023 & 138.7649 \\
2 & 164.7290 & 140.7494 \\
1 & 160.5612 & 147.2391 \\
\hline Obs: & AIC = Akaike e SBC = Schwarz
\end{tabular}

Pela tabela 4 acima, o número de defasagens do VAR dependerá do critério a ser adotado. Neste trabalho, optou-se por seguir o critério de Akaike, pois se perde menos graus de liberdade. Portanto, pode-se concluir que o VAR deve incluir 1 defasagem em cada uma de suas variáveis.

Quanto aos demais parâmetros do VAR, a constante e a tendência, estes foram definidos com base nos mesmos critérios utilizados para a definição do número de defasagens do VAR. O resultado dos testes foi que o melhor modelo deveria incluir uma constante e uma tendência no VAR, da seguinte forma:

$$
\left[\begin{array}{c}
C_{t} \\
P_{t} \\
Y_{t} \\
L_{t}
\end{array}\right]=\left[\begin{array}{l}
A_{10} \\
A_{20} \\
A_{30} \\
A_{40}
\end{array}\right]+\left[\begin{array}{l}
A_{11} A_{12} A_{13} A_{14} \\
A_{21} A_{22} A_{23} A_{24} \\
A_{31} A_{32} A_{33} A_{34} \\
A_{41} A_{45} A_{43} A_{44}
\end{array}\right]\left[\begin{array}{c}
C_{t-1} \\
P_{t-1} \\
Y_{t-1} \\
L_{t-1}
\end{array}\right]+\left[\begin{array}{c}
B_{10} t_{C} \\
B_{20} t_{P} \\
B_{30} t_{Y} \\
B_{40} t_{L}
\end{array}\right]+\left[\begin{array}{c}
e_{t}^{C} \\
e_{t}^{P} \\
e_{t}^{Y} \\
e_{t}^{L}
\end{array}\right]
$$

\footnotetext{
${ }^{14}$ Para especificação do modelo, segundo Hendry (1995), deve-se partir do caso geral para o específico, isto é, deve-se iniciar a análise com um grande número de defasagens e, a partir de testes formais, ir reduzindo o número de parâmetros.

${ }^{15}$ Enders (1995).
} 
Após determinar a melhor especificação do VAR, foi aplicado o modelo de Johansen, cujo objetivo era encontrar os vetores de cointegração. Para tanto, usou-se o teste do traço ( $\lambda$-traço), que indica não somente se há cointegração, mas, se houver, o número de vetores de cointegração existente. Os resultados podem ser vistos na tabela 5 a seguir e referem-se tão somente a primeira equação (relativa ao consumo de energia elétrica).

Tabela 5

Teste $\lambda$-traço

\begin{tabular}{c|c|c|c|c}
\hline Autovalor & Estatística de Teste & \multicolumn{2}{|c|}{ Valores Críticos } & Hipótese Nula \\
\cline { 3 - 4 } & & $5 \%$ & $1 \%$ & No Eq. Coint. \\
\hline 0,789876 & 86,78229 & 62,99 & 70,05 & Nenhuma \\
0,491239 & 39,98054 & 42,44 & 48,45 & Máx. 1 \\
0,321340 & 19,52979 & 25,32 & 30,45 & Máx. 2 \\
\hline
\end{tabular}

De acordo com os resultados acima, verifica-se que: na primeira linha, a hipótese de que não há vetores se cointegrando é rejeitada, tanto a $1 \%$ quanto a 5\%; na segunda, a hipótese de que há no máximo um vetor de cointegração não pode ser rejeitada aos dois níveis de significância escolhidos. Com isso, é identificada a presença de apenas 1 vetor de cointegração, cujos coeficientes desta equação podem ser escritos da seguinte forma (tabela 6):

Tabela 6

Coeficientes normalizados

\begin{tabular}{cccccc}
\hline$C_{t}$ & $K$ & $L_{t}$ & $Y_{t}$ & $P_{t}$ & tendência \\
\hline 1,000000 & $-1,861731$ & 0,147821 & $-0,539003$ & 0,085205 & $-0,044476$ \\
& & $(0,05163)$ & $(0,04862)$ & $(0,02114)$ & $(0,00316)$ \\
\hline
\end{tabular}

* O número em parêntese refere-se ao desvio padrão

Portanto, a equação de cointegração relativa à variável consumo de energia elétrica pode ser escrita no seguinte formato:

$$
C_{t}=1,862-0,148 L_{t}+0,539 Y_{t}-0,085 P_{t}+0,044 t
$$

As estimativas obtidas para todos os coeficientes são estatisticamente significantes e os sinais estão de acordo com os esperados pela teoria. Além disso, a elasticidade-preço de longo prazo da demanda residencial é $-0,085$, o que significa que uma elevação de $1 \%$ nas tarifas gerará uma redução de $0,085 \%$ no consumo residencial. A elasticidade-preço de longo prazo das utilidades domésticas, $-0,148$, é maior que a elasticidade-preço da demanda, o que significa dizer que o impacto de alterações nos preços desses bens têm um efeito maior sobre o consumo de 
energia elétrica residencial do que alterações nas tarifas. Já a elasticidade-renda de longo prazo apresenta valor de 0,539 .

\subsection{Comercial}

Da mesma forma que foi feita no sub-item anterior, foram realizados testes de raiz unitária (ADF) para cada série utilizada, também com as observações em logaritmo. Os resultados dos testes estão na tabela 7 a seguir:

Tabela 7

Testes de raiz unitária $(\mathrm{ADF})$

\begin{tabular}{l|c|c|c|c|c}
\hline Variável & Termos da equação & Número de & Estatística de & \multicolumn{2}{|c}{ Valor Crítico } \\
\cline { 5 - 6 }$(\mathrm{em} \mathrm{log})$ & & defasagens & teste (ADF) & $5 \%$ & $1 \%$ \\
\hline$C_{t}$ & Constante e tendência & 1 & $-3,121$ & $-3,573$ & $-4,308$ \\
$P_{t}$ & Constante e tendência & 0 & $-1,981$ & $-3,567$ & $-4,295$ \\
$Y_{t}$ & Constante e tendência & 0 & $-2,450$ & $-3,567$ & $-4,295$ \\
$L_{t}$ & Constante e tendência & 0 & $-1,700$ & $-3,567$ & $-4,295$ \\
\hline
\end{tabular}

Nos resultados apresentados na tabela 7, a hipótese de presença de raiz unitária não pode ser rejeitada para nenhuma das quatro séries analisadas, tanto a $1 \%$ quanto a 5\%, o que indica que nenhuma delas é estacionária. Foram realizados, também, teste de raiz unitária (ADF) para as séries em diferenças e o resultado obtido em todos os casos foi que, para cada série, rejeitou-se a hipótese nula (raiz unitária). Com isso, conclui-se que todas as séries são I(1). Para conferir, veja a tabela 8 abaixo:

Tabela 8

Testes de raiz unitária (ADF)

\begin{tabular}{l|l|c|c|c|c}
\hline Variável & Termos da equação & Número de & Estatística de & \multicolumn{2}{|c}{ Valor Crítico } \\
\cline { 3 - 5 }$(\mathrm{em} \mathrm{log})$ & & defasagens & teste (ADF) & $5 \%$ & $1 \%$ \\
\hline$\Delta C_{t}$ & Constante & 0 & -3.272 & $-2,966$ & $-3,675$ \\
$\Delta P_{t}$ & Constante e tendência & 0 & -4.925 & $-3,573$ & $-4,308$ \\
$\Delta Y_{t}$ & Constante & 0 & -3.375 & $-2,966$ & $-3,675$ \\
$\Delta L_{t}$ & Constante & 0 & -5.108 & $-2,966$ & $-3,675$ \\
\hline
\end{tabular}

Para a definição da ordem do VAR foi utilizado o critério de informação de Akaike, como no caso residencial. Por este critério foi definido que o VAR utilizado no modelo de Johansen deveria conter as séries defasadas em 2 períodos. Foi definido, também, que uma constante e um componente de tendência deveriam ser incluídos no modelo. Na tabela 9, abaixo, são apresentadas as estatísticas que permitiram definir o número de defasagens do VAR. 
Tabela 9

Definição do número de defasagens do VAR

\begin{tabular}{ccc}
\hline Defasagens & AIC & SBC \\
\hline 3 & 179.2767 & 144.6394 \\
2 & 176.4564 & 152.4767 \\
1 & 183.6009 & 170.2788 \\
\hline
\end{tabular}

Assim, pode-se expressar o VAR da seguinte forma:

$$
\begin{gathered}
{\left[\begin{array}{l}
C_{t} \\
P_{t} \\
Y_{t} \\
L_{t}
\end{array}\right]=\left[\begin{array}{l}
A_{10} \\
A_{20} \\
A_{30} \\
A_{40}
\end{array}\right]+\left[\begin{array}{c}
A_{11} A_{12} A_{13} A_{14} \\
A_{21} A_{22} A_{23} A_{24} \\
A_{31} A_{32} A_{33} A_{34} \\
A_{41} A_{45} A_{43} A_{44}
\end{array}\right]\left[\begin{array}{c}
C_{t-1} \\
P_{t-1} \\
Y_{t-1} \\
L_{t-1}
\end{array}\right]} \\
+\left[\begin{array}{c}
B_{11} B_{12} B_{13} B_{14} \\
B_{21} B_{22} B_{23} B_{24} \\
B_{31} B_{32} B_{33} B_{34} \\
B_{41} B_{45} B_{43} B_{44}
\end{array}\right]\left[\begin{array}{l}
C_{t-2} \\
P_{t-2} \\
Y_{t-2} \\
L_{t-2}
\end{array}\right]+\left[\begin{array}{l}
B_{10} t_{C} \\
B_{20} t_{P} \\
B_{30} t_{Y} \\
B_{40} t_{L}
\end{array}\right]+\left[\begin{array}{c}
e_{t}^{C} \\
e_{t}^{P} \\
e_{t}^{Y} \\
e_{t}^{L}
\end{array}\right]
\end{gathered}
$$

Após determinar a melhor especificação do VAR, na tabela 10, a seguir, são apresentados os resultados do teste responsável por identificar o número de vetores de cointegração existentes.

Tabela 10

Teste $\lambda$-traço

\begin{tabular}{c|c|c|c|c}
\hline Autovalor & Estatística de Teste & \multicolumn{2}{|c|}{ Valores Críticos } & Hipótese Nula \\
\cline { 3 - 4 } & & $5 \%$ & $1 \%$ & No $^{\circ}$ Eq. Coint. \\
\hline 0,663715 & 75,52926 & 62,99 & 70,05 & Nenhuma \\
0,496703 & 43,92513 & 42,44 & 48,45 & Max. 1 \\
0,378195 & 24,01448 & 25,32 & 30,45 & Max. 2 \\
\hline
\end{tabular}

Pelo teste do traço, verifica-se que, com $1 \%$ de significância, há apenas uma equação de cointegração para as séries analisadas. Os coeficientes da equação de cointegração são apresentados na tabela 11 a seguir:

Tabela 11

Coeficientes normalizados

\begin{tabular}{cccccc}
\hline$C_{t}$ & $L_{t}$ & $Y_{t}$ & $P_{t}$ & tendência & $K$ \\
\hline 1,000000 & 0,294362 & $-0,635861$ & 0,174464 & $-0,017937$ & $-3,289837$ \\
& $(0,04621)$ & $(0,05014)$ & $(0,02959)$ & $(0,00403)$ & \\
\hline
\end{tabular}

* O número em parêntese refere-se ao desvio padrão 
Portanto, a equação de cointegração relativa à variável consumo de energia elétrica pode ser escrita no seguinte formato:

$$
C_{t}=3,290-0,174 P_{t}+0,636 Y_{t}-0,294 L_{t}+0,018 t
$$

As estimativas obtidas para todos os coeficientes são estatisticamente significativas e os sinais estão de acordo com os esperados pela teoria. Além disso, o valor encontrado para a elasticidade-preço de longo prazo da demanda comercial, -0,174, é superior, em módulo, à elasticidade-preço estimada para a demanda residencial, $-0,085$. Já a elasticidade-renda de longo prazo comercial, 0,636, é um pouco maior que a obtida no caso anterior, 0,539. Por fim, a elasticidade-preço de material elétrico estimada é -0,294, que é superior à elasticidade do preço do bem intensivo em energia elétrica (utilidades domésticas) obtido para a demanda residencial, $-0,148$.

A relação entre a influência das variáveis nas elasticidades se mantém. Isto é, a renda, representada pelo PIB, continua sendo a variável que causa maior variação no consumo de energia elétrica, seguida do preço do bem intensivo em energia elétrica, que, por sua vez, é seguida pela tarifa.

\subsection{Industrial}

No caso industrial foram estimados dois modelos distintos. A diferença entre eles consiste na inclusão ou não do preço do bem substituto. O primeiro modelo estimado não utiliza o preço do bem substituto e o segundo o inclui. Assim, com relação ao teste de raiz unitária, os testes são equivalentes para os dois modelos, assim como foi feito para os casos residencial e comercial, com a diferença da inclusão da série $S$. Já o restante das análises foi feita para cada modelo em separado.

Assim, da mesma forma que foi feita nos itens anteriores, foram realizados testes de raiz unitária (ADF) para cada série utilizada, também com as observações em logaritmo. Os resultados dos testes estão na tabela 12 a seguir:

Tabela 12

Testes de raiz unitária (ADF)

\begin{tabular}{l|c|c|c|c|c}
\hline $\begin{array}{l}\text { Variável } \\
(\mathrm{em} \log )\end{array}$ & Termos da equação & $\begin{array}{c}\text { Número de } \\
\text { defasagens }\end{array}$ & $\begin{array}{c}\text { Estatística de } \\
\text { teste (ADF) }\end{array}$ & \multicolumn{2}{|c}{ Valor Crítico } \\
\cline { 4 - 6 }$C_{t}$ & Constante e tendência & 0 & $-1,265$ & $-3,567$ & $-4,295$ \\
$P_{t}$ & Constante e tendência & 0 & $-2,770$ & $-3,567$ & $-4,295$ \\
$Y_{t}$ & Constante e tendência & 0 & $-2,450$ & $-3,567$ & $-4,295$ \\
$L_{t}$ & Constante e tendência & 0 & $-2,626$ & $-3,567$ & $-4,295$ \\
$S_{t}$ & Constante e tendência & 1 & $-2,307$ & $-3,573$ & $-4,308$ \\
\hline
\end{tabular}


Nos resultados apresentados na tabela 12, a hipótese de presença de raiz unitária não pode ser rejeitada para nenhuma das cinco séries analisadas, tanto a $1 \%$ quanto a $5 \%$, o que indica que nenhuma delas é estacionária. Foram realizados, também, teste de raiz unitária (ADF) para as séries em diferenças e o resultado obtido em todos os casos foi que, para cada série, rejeitou-se a hipótese nula (raiz unitária). Com isso, conclui-se que todas as séries são I(1). Para conferir, veja a tabela 13 abaixo:

Tabela 13

Testes de raiz unitária (ADF)

\begin{tabular}{l|c|c|c|c|c}
\hline Variável & Termos da equação & \multirow{2}{*}{$\begin{array}{c}\text { Número de } \\
\text { (em log) }\end{array}$} & & $\begin{array}{c}\text { Estatística de } \\
\text { defasagens }\end{array}$ & \multicolumn{2}{|c}{ Valor Crítico } \\
\cline { 4 - 6 } & & 0 & -5.476 & $5 \%$ & $1 \%$ \\
\hline$\Delta C_{t}$ & Constante e tendência & 0 & -6.348 & $-3,573$ & $-4,308$ \\
$\Delta P_{t}$ & Constante e tendência & 0 & -4.477 & $-3,573$ & $-4,308$ \\
$\Delta Y_{t}$ & Constante e tendência & 0 & -5.968 & $-3,573$ & $-4,308$ \\
$\Delta L_{t}$ & Constante e tendência & 0 & -5.286 & $-3,573$ & $-4,308$ \\
$\Delta S_{t}$ & Constante e tendência & 0 & 0
\end{tabular}

A partir daqui os modelos são especificados e estimados separadamente. Assim, para o primeiro modelo, o que não inclui o preço do bem substituto, para a definição do modelo mais adequado para a análise de cointegração foi utilizado o critério de informação de Akaike, como nos casos residencial e comercial. Por este critério foi definido que o VAR utilizado no modelo de Johansen deve conter as séries defasadas em 2 períodos. Foi definido também, que uma constante deveria ser incluída ao VAR. Na tabela 14, abaixo, são apresentadas as estatísticas que permitiram definir o número de defasagens do VAR.

Tabela 14

Definição do número de defasagens do VAR

\begin{tabular}{ccc}
\hline Defasagens & AIC & SBC \\
\hline 3 & 152.7791 & 118.1418 \\
2 & 151.3648 & 137.3851 \\
1 & 163.4722 & 150.1501 \\
\hline
\end{tabular}

Assim, pode-se expressar o VAR da seguinte forma:

$$
\left[\begin{array}{l}
C_{t} \\
P_{t} \\
Y_{t} \\
L_{t}
\end{array}\right]=\left[\begin{array}{l}
A_{10} \\
A_{20} \\
A_{30} \\
A_{40}
\end{array}\right]+\left[\begin{array}{c}
A_{11} A_{12} A_{13} A_{14} \\
A_{21} A_{22} A_{23} A_{24} \\
A_{31} A_{32} A_{33} A_{34} \\
A_{41} A_{45} A_{43} A_{44}
\end{array}\right]\left[\begin{array}{c}
C_{t-1} \\
P_{t-1} \\
Y_{t-1} \\
L_{t-1}
\end{array}\right]
$$




$$
+\left[\begin{array}{c}
B_{11} B_{12} B_{13} B_{14} \\
B_{21} B_{22} B_{23} B_{24} \\
B_{31} B_{32} B_{33} B_{34} \\
B_{41} B_{45} B_{43} B_{44}
\end{array}\right]\left[\begin{array}{c}
C_{t-2} \\
P_{t-2} \\
Y_{t-2} \\
L_{t-2}
\end{array}\right]+\left[\begin{array}{c}
e_{t}^{C} \\
e_{t}^{P} \\
e_{t}^{Y} \\
e_{t}^{L}
\end{array}\right]
$$

E na tabela 15, são apresentados os resultados do teste responsável por identificar o número de vetores de cointegração existente no primeiro caso.

Tabela 15

Teste $\lambda$-traço

\begin{tabular}{c|c|c|c|c}
\hline Autovalor & Estatística de Teste & \multicolumn{2}{|c|}{ Valores Críticos } & Hipótese Nula \\
\cline { 3 - 4 } & & $5 \%$ & $1 \%$ & N $^{o}$ Eq. Coint. \\
\hline 0,628059 & 62,59523 & 53,12 & 60,16 & Nenhuma \\
0,534358 & 33,91363 & 34,91 & 41,07 & Max. 1 \\
0,291720 & 11,74781 & 19,96 & 24,60 & Max. 2 \\
\hline
\end{tabular}

Pelo teste do traço, verifica-se que, com $1 \%$ de significância, há apenas uma equação de cointegração para as séries analisadas. Os coeficientes do vetor de cointegração são apresentados na tabela 16 a seguir.

Tabela 16

Coeficientes normalizados

\begin{tabular}{ccccc}
\hline$C_{t}$ & $L_{t}$ & $Y_{t}$ & $P_{t}$ & $K$ \\
\hline$-1,000000$ & 0,669504 & 1,717535 & $-0,128672$ & $-5,795044$ \\
& $(0,12809)$ & $(0,07597)$ & $(0,07933)$ & $(1,01045)$ \\
\hline
\end{tabular}

* O número em parêntese refere-se ao desvio padrão

Portanto, a equação de cointegração relativa à variável consumo de energia elétrica pode ser escrita no seguinte formato:

$$
C_{t}=-5,795-0,129 P_{t}+1,718 Y_{t}+0,670 L_{t}
$$

As estimativas obtidas para todos os coeficientes são estatisticamente significativas, exceto para a série de preços. Assim, a elasticidade-preço obtida, -0, 129, apesar de apresentar valor semelhante às estimadas anteriormente, não é significativamente diferente de zero aos níveis de significância de $1 \%$ e $5 \%$, o que significa dizer que naõ se pode rejeitar a hipótese de que as alterações na tarifa industrial não têm efeito sobre o consumo de energia elétrica deste segmento.

Quanto à elasticidade-renda, 1,718, sua magnitude é significamente superior às encontradas nos dois casos anteriores, mas seu sinal é coerente com o da teoria. Já a elasticidade-preço do bem intensivo em energia elétrica (máquinas e equipamentos) 
apresenta sinal oposto ao esperado. Em outras palavras, este fato indica que uma elevação no preço de máquinas e equipamentos gera uma elevação no consumo industrial de energia, o que é estranho.

Como estes resultados podem se dever a algum erro na especificação do modelo, principalmente no que concerne à não inclusão de alguma outra variável relevante para a análise, foi incluído o preço do produto substituto da energia elétrica. Para isso, foi utilizado o índice de preços de combustíveis e lubrificantes.

Assim, para o segundo modelo, que inclui o preço do bem substituto, para a definição do modelo mais adequado para a análise de cointegração, foi utilizado o critério de informação de Akaike. Por este critério foi definido que o VAR utilizado no modelo de Johansen deve conter as séries defasadas em 2 períodos. Foi definido também que uma constante e uma tendência deveriam ser incluídas ao VAR. Na tabela 17, abaixo, são apresentadas as estatísticas que permitiram definir o número de defasagens do VAR.

Tabela 17

Definição do número de defasagens do VAR

\begin{tabular}{ccc}
\hline Defasagens & AIC & SIC \\
\hline 3 & 158.0763 & 104.7882 \\
2 & 141.8379 & 105.2023 \\
1 & 145.6578 & 125.6747 \\
\hline
\end{tabular}

Assim, pode-se expressar o VAR da seguinte forma:

$$
\begin{gathered}
{\left[\begin{array}{l}
C_{t} \\
P_{t} \\
Y_{t} \\
L_{t} \\
S_{t}
\end{array}\right]=\left[\begin{array}{l}
A_{10} \\
A_{20} \\
A_{30} \\
A_{40} \\
A_{50}
\end{array}\right]+\left[\begin{array}{l}
A_{11} A_{12} A_{13} A_{14} A_{15} \\
A_{21} A_{22} A_{23} A_{24} A_{25} \\
A_{31} A_{32} A_{33} A_{34} A_{35} \\
A_{41} A_{45} A_{43} A_{44} A_{45} \\
A_{51} A_{55} A_{53} A_{41} A_{55}
\end{array}\right]\left[\begin{array}{c}
C_{t-1} \\
P_{t-1} \\
Y_{t-1} \\
L_{t-1} \\
S_{t-1}
\end{array}\right]} \\
+\left[\begin{array}{l}
B_{11} B_{12} B_{13} B_{14} \\
B_{21} B_{22} B_{23} B_{24} \\
B_{31} B_{32} B_{33} B_{34} \\
B_{41} B_{45} B_{43} B_{44} \\
B_{51} B_{55} B_{53} B_{54}
\end{array}\right]\left[\begin{array}{l}
C_{t-2} \\
P_{t-2} \\
Y_{t-2} \\
L_{t-2} \\
S_{t-2}
\end{array}\right]+\left[\begin{array}{l}
B_{10} t_{C} \\
B_{20} t_{P} \\
B_{30} t_{Y} \\
B_{40} t_{L} \\
B_{50} t_{S}
\end{array}\right]+\left[\begin{array}{c}
e_{t}^{C} \\
e_{t}^{P} \\
e_{t}^{Y} \\
e_{t}^{L} \\
e_{t}^{S}
\end{array}\right]
\end{gathered}
$$

E na tabela 18, são apresentados os resultados do teste responsável por identificar o número de vetores de cointegração existente no segundo caso. 
Tabela 18

Teste $\lambda$-traço

\begin{tabular}{c|c|c|c|c}
\hline Autovalor & Estatística de Teste & \multicolumn{2}{|c|}{ Valores Críticos } & Hipótese Nula \\
\cline { 3 - 4 } & & $5 \%$ & $1 \%$ & N $^{\circ}$ Eq. Coint. \\
\hline 0,869367 & 114,5506 & 77,74 & 85,78 & Nenhuma \\
0,674811 & 55,525 & 54,64 & 61,24 & Máx. 1 \\
0,354398 & 22,480 & 34,55 & 40,49 & Máx. 2 \\
\hline
\end{tabular}

Pelo teste do traço, verifica-se que, com $1 \%$ de significância, há apenas uma equação de cointegração para as séries analisadas. Os coeficientes da equação de cointegração são apresentados na tabela 19 a seguir.

Tabela 19

Coeficientes normalizados

\begin{tabular}{ccccccc}
\hline$C_{t}$ & $L_{t}$ & $Y_{t}$ & $S_{t}$ & $P_{t}$ & tendência & $K$ \\
\hline$-1,000000$ & $-0,464828$ & 1,915830 & $-0,026630$ & $-0,544613$ & 0,065675 & 2,361704 \\
& $(0,09887)$ & $(0,14663)$ & $(0,00671)$ & $(0,07305)$ & & \\
\hline
\end{tabular}

* O número em parêntese refere-se ao desvio padrão

Portanto, a equação de cointegração relativa à variável consumo de energia elétrica pode ser escrita no seguinte formato:

$$
C_{t}=2,362-0,545 P_{t}+1,916 Y_{t}-0,465 L_{t}-0,027 S_{t}+0,066 t
$$

A inclusão do preço do bem substituto alterou substancialmente os resultados obtidos no caso anterior. As estimativas obtidas para todos os coeficientes são, agora, estatisticamente significantes e com os sinais de acordo com os esperados pela teoria. Além disso, a elasticidade-preço de longo prazo da demanda industrial passou a ter o seu valor bem superior a todos os já estimados, $-0,545$, mostrando que ainda que inelástica, a energia elétrica parece poder ser substituída de alguma forma por outra fonte de energia.

Já a elasticidade-renda, 1,916, ficou ainda maior do que a estimada anteriormente, o que, de acordo com a literatura, é demasiadamente alta. Esperava-se encontrar algo em torno de um. E por fim, as elasticidades-preço de longo prazo das máquinas e equipamentos, $-0,465$, e dos combustíveis, -0, 0267 estão dentro do esperado.

\subsection{Comparações}

Nesta seção será feita uma comparação entre as elasticidades de longo prazo obtidas no presente trabalho, nos estudos para a Dinamarca, a Grã-Bretanha, o 
Paraguai, a Costa Rica e os Estados Unidos, e nas pesquisas de Modiano (1984) e Andrade e Lobão (1997) para o caso brasileiro. Cabe observar, contudo, que as elasticidades de longo prazo calculadas para os outros países, com exceção dos Estados Unidos, não foram divididas por classe de consumo.

As elasticidades-preço de longo prazo aqui encontradas são, com exceção da obtida para o segundo modelo estimado para a classe industrial $(-0,545)$, de magnitude inferior às obtidas para os demais países considerados. Para a Dinamarca, Paraguai e Costa Rica o valor destas elasticidades é de aproximadamente $-0,5$, enquanto que para a Grã-Bretanha este valor é de $-0,893$. Os valores encontrados para os Estados Unidos também são de magnitude superior aos obtidos neste artigo. Para a classe residencial as elasticidades estimadas para os Estados Unidos oscilaram entre $-0,7$ e $-1,1$, enquanto que para a classe industrial estes valores variavam entre -0.8 e $-0,9$.

Para as elasticidades-renda de longo prazo, os valores encontrados neste estudo são diferentes entre as classes de consumo. Estes variaram entre 0,539 para a classe residencial, a 1,916, para o segundo modelo estimado para a demanda industrial.

Para a Dinamarca e para a Grã-Bretanha os valores desta elasticidade, para a demanda total por energia elétrica foram, respectivamente 1,213 e 1,166. Os resultados obtidos para o Paraguai e para a Costa Rica oscilaram em torno de 0,5 , valor que se assemelha mais à elasticidade estimada nesta pesquisa para a classe comercial. Para os Estados Unidos estes valores não estavam disponíveis.

Os resultados obtidos para a demanda da classe residencial, apesar da diferente metodologia adotada e da utilização de uma variável adicional (preço de utilidades domésticas), são de magnitude inferior aos obtidos por Modiano (1984) para as elasticidades-preço e renda no longo prazo. Cabe destacar, ainda, que todos os coeficientes são estatisticamente significativos a $5 \%$ e 1\%. Já em relação aos resultados obtidos por Andrade e Lobão (1997), que utilizam a mesma metodologia aqui empregada, há diferenças, mas no sentido oposto. As elasticidades obtidas neste trabalho são superiores às estimadas por estes autores. As elasticidadespreço e renda de longo prazo obtidas por eles foram respectivamente $-0,05084 \mathrm{e}$ 0,2132 .

Para as demandas comercial e industrial apenas Modiano obteve estimativas para as elasticidades de longo prazo. Com relação à demanda comercial por energia elétrica, a elasticidade-preço de longo prazo é igual a -0,183, enquanto a elasticidade-renda é 1,068.

Para a classe de consumo industrial, as elasticidades-renda e preço obtidas por Modiano são, respectivamente, $-0,222$ e 1,36. Os resultados aqui obtidos para os dois modelos estimados para a demanda industrial também apresentam 
elasticidades-renda superiores a 1 , e superiores às elasticidades-renda obtidas para as demais classes de consumo. Quanto à elasticidade-preço um dos modelos estimados apresentou valor inferior (em módulo) à de Modiano e o outro um valor maior $(-0,545)$.

\section{Previsões para os Consumos de Energia Elétrica}

Com a finalidade de realizar previsões para o consumo de energia elétrica, para os três tipos de classe, foi estimado o modelo de correção de erros vetoriais (MCEV) a partir do VAR utilizado para o teste de cointegração do modelo de Johansen. Conforme Engle e Granger (1987) demonstraram, qualquer série cointegrada tem uma representação de um MCEV. Assim, pelo fato das variáveis se cointegrarem, existe algum processo de ajuste entre o curto prazo e o longo prazo. O MCEV, então, fornece a velocidade de ajustamento dos desvios de curto prazo em relação à trajetória de longo prazo.

Assim sendo, neste trabalho, para cada uma das relações de cointegração apresentadas no item anterior, foi estimado um MCEV. Como a variável de interesse para a realização de previsões é o consumo de energia elétrica, foram realizadas estimações de MCEV para esta variável. No caso residencial: $\Delta C_{t}=a u_{t-1}+e_{t}^{C}$; nos casos comercial e industrial (primeiro modelo) estes podem ser expressos por: $\Delta C_{t}=a u_{t-1}+b \Delta C_{t-1}+c \Delta P_{t-1}+d \Delta Y_{t-1}+e \Delta L_{t-1}+e_{t}^{C}$; e no caso industrial (segundo modelo) pode-se expressar como sendo: $\Delta C_{t}=a u_{t-1}+b \Delta C_{t-1}+c \Delta P_{t-1}+$ $d \Delta Y_{t-1}+e \Delta L_{t-1}+f \Delta S_{t-1}+e_{t}^{C}$. Estes modelos têm as seguintes características: todas as variáveis são estacionárias, uma vez que são variáveis $I(0)$ em diferenças; os resíduos, por serem derivados da equação de cointegração, são, por definição, estacionários; e as especificações dos MCEV seguem a especificação dos VARs utilizados na realização dos testes de cointegração de Johansen, mostrando que os MCEV são sub-modelos destes VARs.

\subsection{Modelos de correção de erros vetoriais}

\section{Residencial}

Os resultados estimados são apresentados na tabela 20 abaixo: 
Tabela 20

Estimação de $\Delta C_{t}$

\begin{tabular}{c|c|l}
\hline Variável Explicativa & Coeficiente & \multicolumn{1}{|c}{ Testes } \\
\hline$u_{t-1}$ & $-0,10977$ & Normalidade $=1,9477(0,378)$ \\
& $(0,02150)$ & Correl. Serial $=0,8432(0,358)$ \\
\hline$K$ & 0,78469 & Heteroc. $=0,5144(0,473)$ \\
& $(0,13841)$ & \\
\cline { 1 - 1 } & & $\mathrm{F}=26,0668(0,000)$ \\
& & $R^{2}=0,4821$ \\
\hline
\end{tabular}

OBS: o número em parêntese na segunda coluna refere-se ao desvio padrão e o da terceira coluna, ao p-value. Além disso, "u" são os resíduos da relação de cointegração.

Portanto, a equação de correção de erro relativa à variável energia elétrica pode ser escrita no seguinte formato:

$$
\Delta C_{t}=0,785-0,110 u_{t-1}+e_{t}^{C}
$$

Pelo MCEV estimado, a velocidade de ajustamento em relação ao equilíbrio de longo prazo é $-0,110$, ou seja $11 \%$ do desequilíbrio de curto prazo em relação à trajetória de longo prazo é corrigido a cada período. Este fato indica que o ajuste total dos desvios do equilíbrio de longo prazo levaria cerca de nove anos.

Cabe ainda ressaltar que os resíduos do MCEV estimados são normalmente distribuídos, homocedásticos e não-autocorrelacionados conforme mostram os testes do Multiplicador de Lagrange (LM) para correlação serial, o de White para heterocedasticidade e o teste de Jarque-Bera para normalidade dos resíduos. ${ }^{16}$

\section{Comercial}

Para a demanda comercial de energia elétrica foi estimado um MCEV, cujos resultados são apresentados na tabela 21 abaixo:

\footnotetext{
${ }^{16}$ Hendry (1995).
} 
Tabela 21

Estimação de $\Delta C_{t}$

\begin{tabular}{c|c|l}
\hline Variável Explicativa & Coeficiente & Testes \\
\hline $\mathrm{K}$ & 1,0777 & Normalidade $=0,041926(0,979)$ \\
& $(0,39587)$ & Correl. Serial $=0,57989(0,446)$ \\
& 0,047071 & Heteroc. $=0,58212(0,445)$ \\
& $(0,017644)$ & \\
\cline { 1 - 2 } & \multirow{2}{*}{$\mathrm{F}=7,8907(0,000)$} \\
& 0,46093 & \multirow{2}{*}{$R^{2}=0,63172$} \\
\hline$\Delta C_{t-1}$ & $0,16371)$ & \\
\hline$\Delta P_{t-1}$ & $(0,02921)$ & \\
\hline$\Delta Y_{t-1}$ & $-0,230567$ & \\
& $(0,15868)$ & \\
\hline$\Delta L_{t-1}$ & 0,028497 & \\
& $(0,04428)$ & \\
\hline
\end{tabular}

OBS: o número em parêntese na segunda coluna refere-se ao desvio padrão e o da terceira coluna, ao p-value. Além disso, "u" são os resíduos da relação de cointegração.

Portanto, a equação de correção de erro relativa à variável energia elétrica pode ser escrita no seguinte formato:

$$
\begin{aligned}
\Delta C_{t} & =1,078+0,047 u_{t-1}+0,461 \Delta C_{t-1}+0,020 \Delta P_{t-1}-0,231 \Delta Y_{t-1} \\
& +0,028 \Delta L_{t-1}+e_{t}^{C}
\end{aligned}
$$

Pelo MCEV, a velocidade de ajustamento deste modelo é de 0,047071, indicando que aproximadamente $4,7 \%$ dos desvios da trajetória de longo prazo do consumo comercial de energia elétrica são corrigidos a cada ano. Isto quer dizer que o ajuste total dos desvios do equilíbrio de longo prazo levaria cerca de 21 anos. O modelo estimado apresenta uma constante devido ao fato do modelo original ter uma tendência em sua formulação.

Cabe ainda ressaltar que os resíduos do MCEV estimado são normalmente distribuídos, homocedásticos e não-autocorrelacionados conforme mostram os testes do Multiplicador de Lagrange (LM) para correlação serial, o de White para heterocedasticidade e o teste de Jarque-Bera para normalidade dos resíduos. 


\section{Industrial}

Para a demanda industrial por energia elétrica foi estimado um MCEV, para cada um dos dois VARs utilizados na análise de cointegração, como pode ser visto nas tabelas 22 (não inclui a diferença da série $\mathrm{S}$, que é o índice de preços de combustíveis e lubrificantes) e 23 (inclui).

A inclusão da constante no segundo modelo (tabela 21) se refere à especificação do VAR com um componente de tendência. No primeiro modelo, contudo (tabela 22), pelo fato do VAR só possuir uma constante, o MCEV estimado não possui a constante.

Tabela 22

Estimação de $\Delta C_{t}$

\begin{tabular}{c|c|l}
\hline Variável Explicativa & Coeficiente & \multicolumn{1}{|c}{ Testes } \\
\hline$u_{t-1}$ & $-0,067255$ & Normalidade $=0,55148(0,759)$ \\
& $(0,47456)$ & Correl. Serial=5,8785(0,015) \\
& 0,830411 & Heteroc. $=1,2786(0,258)$ \\
& $(0,24577)$ & \\
\hline$\Delta C_{t-1}$ & 0,034326 & $\mathrm{~F}=3,8890(0,014)$ \\
& $(0,07196)$ & $R^{2}=0,39326$ \\
\hline$Y_{t-1}$ & $-0,220372$ & \\
& $(0,32599)$ & \\
\hline$L_{t-1}$ & $-0,007866$ & \\
& $(0,14585)$ & \\
\hline
\end{tabular}

OBS: o número em parêntese na segunda coluna refere-se ao desvio padrão

e o da terceira coluna, ao p-value. Além disso, "u" são os resíduos da

relação de cointegração.

Portanto, a equação de correção de erro relativa à variável energia elétrica pode ser escrita no seguinte formato:

$$
\begin{aligned}
\Delta C_{t} & =-0,067 u_{t-1}+0,830 \Delta C_{t-1}+0,034 \Delta P_{t-1}-0,220 \Delta Y_{t-1} \\
& -0,008 \Delta L_{t-1}+e_{t}^{C}
\end{aligned}
$$

Pelo MCEV, a velocidade de ajustamento do modelo é $-0,067255$. O coeficiente, porém, não é estatisticamente diferente de zero a $5 \%$ de significância. Aliás, somente o coeficiente da variável dependente defasada é estatisticamente significativo.

Cabe ainda ressaltar que os resíduos do MCEV estimado são normalmente distribuídos, homocedásticos e não-autocorrelacionados conforme mostram os tes- 
tes do Multiplicador de Lagrange (LM) para correlação serial, o de White para heterocedasticidade e o teste de Jarque-Bera para normalidade dos resíduos.

Tabela 23

Estimação de $\Delta C_{t}$

\begin{tabular}{c|c|l}
\hline Variável Explicativa & Coeficiente & \multicolumn{1}{|c}{ Testes } \\
\hline$K$ & 0,16266 & Normalidade $=3,0142(0,222)$ \\
& $(0,30924)$ & Correl. Serial $=0,63926(0,424)$ \\
& 0,00014 & Heteroc. $=0,098939(0,753)$ \\
& $(0,038159)$ & \\
\hline$u_{t-1}$ & $-0,034508$ & $\mathrm{~F}=5,7398(0,001)$ \\
& $(0,30306)$ & \multirow{2}{*}{$R^{2}=0,65674$} \\
\hline$C_{t-1}$ & $-0,014700$ & \\
\hline$P_{t-1}$ & $(0,06027)$ & \\
\hline$Y_{t-1}$ & $-0,155812$ & \\
& $(0,36496)$ & \\
\hline$S_{t-1}$ & $-0,008844$ & \\
& $(0,01272)$ & \\
\hline$L_{t-1}$ & $-0,002009$ & \\
& $(0,11044)$ & \\
\hline
\end{tabular}

OBS: o número em parêntese na segunda coluna refere-se ao desvio padrão e o da terceira coluna, ao p-value. Além disso, "u" são os resíduos da relação de cointegração.

Portanto, a equação de correção de erro relativa à variável energia elétrica pode ser escrita no seguinte formato:

$$
\begin{aligned}
\Delta C_{t} & =0,163+0,00014 u_{t-1}-0,035 \Delta C_{t-1}-0,015 \Delta P_{t-1}-0,156 \Delta Y_{t-1} \\
& -0,002 \Delta L_{t-1}-0,009 S_{t-1}+e_{t}^{C}
\end{aligned}
$$

Pelo MCEV estimado, a velocidade de ajustamento estimada é muito pequena, além de não ser estatisticamente significativa. Por outro lado, o modelo estimado apresenta boa qualidade de ajuste dos dados evidenciado pelo $R^{2}=0,65674$. Além disso, pode-se concluir que os resíduos são normalmente distribuídos, homocedásticos e não correlacionados serialmente.

Desta forma, como se pode observar pelas tabelas 22 e 23, percebe-se que para os dois modelos para a classe industrial os resíduos das relações de cointegração estimadas não têm coeficientes estatisticamente significativos na dinâmica de curto prazo. Consequentemente as relações de longo prazo podem não ser úteis na 
determinação das dinâmicas de curto prazo e as previsões que serão realizadas no próximo item podem não ser realistas.

\subsection{Previsões}

A partir dos MCEV estimados no item 5.1, para as diferentes classes de consumo de energia elétrica, foram realizadas previsões, primeiro, para os anos de 2000 e 2001 e, depois, para o período compreendido entre 2002 e 2005.

Para derivar estas previsões foram utilizadas algumas hipóteses sobre as variáveis do modelo, que basearam nas premissas realizadas pela Eletrobrás (2001). Para o crescimento do PIB, supôs-se que crescerá a uma taxa de $2 \%$ no ano em 2000, 2,5\% no ano em 2001 e de $5 \%$ ao ano de 2002 a 2005. Para às tarifas de energia elétrica, considerou-se uma elevação de $5 \%$ ao ano. Além disso, assumiu-se que o preço real dos bens intensivos em energia elétrica se manteve constante ao nível de 1999.

Como as observações para o ano de 2000 não foram incluídas nas amostras utilizadas nas estimações, pôde ser feita uma comparação entre os valores previstos pelos modelos estimados para o ano de 2000 e os valores efetivamente observados neste ano, como pode ser observado na tabela 24 , abaixo.

Tabela 24

Previsões para o ano 2000

\begin{tabular}{ccccc}
\hline $\begin{array}{c}\text { Classe } \\
\text { de Consumo }\end{array}$ & $\begin{array}{c}\text { Valor Observado } \\
(\mathrm{GWh})\end{array}$ & $\begin{array}{c}\text { Valor Previsto } \\
(\mathrm{GWh})\end{array}$ & $\begin{array}{c}\text { Diferença } \\
(\mathrm{GWh})^{17}\end{array}$ & $\begin{array}{c}\text { Diferença Percentual } \\
(\%)\end{array}$ \\
\hline Residencial & 83,494 & 82,7 & $-0,8$ & $-0,97$ \\
Comercial & 47,437 & 45,4 & 2,1 & 4,44 \\
Industrial & 131,195 & 124,2 & 7,0 & 5,30 \\
\hline
\end{tabular}

O que se pode observar pela tabela 24 é que a melhor previsão gerada, em comparação com o valor efetivamente observado, é a do modelo estimado para a classe residencial. A diferença entre o valor observado e o previsto é de apenas 0,97\%. Quanto às previsões geradas pelos demais modelos, elas não se mostraram tão precisas quanto o caso residencial, mas a dispersão não é tão significativa, apontando que o modelo é um bom previsor.

Já para o ano de 2001, a comparação entre as previsões e o consumo efetivo são apresentados na tabela 25 , a seguir. 
Tabela 25

Previsões para o ano 2001

\begin{tabular}{ccccc}
\hline Classe & Valor Observado & Valor Previsto & Diferença & Diferença Percentual \\
\hline de Consumo & $(\mathrm{GWh})^{18}$ & $(\mathrm{GWh})$ & $(\mathrm{GWh})$ & $(\%)$ \\
\hline Residencial & 75,448 & 89,1 & $-13,7$ & $-15,32$ \\
Comercial & 45,199 & 47,3 & $-2,1$ & $-4,44$ \\
Industrial & 123,716 & 125,1 & -1.4 & -1.11 \\
\hline
\end{tabular}

Como se pode notar, a previsão no segmento residencial foi prejudicada pelo racionamento de energia elétrica iniciado na metade de 2001. Já para as demais classes as previsões geradas continuaram satisfatórias.

Nas tabelas 26, 27 e 28, abaixo, encontram-se as previsões de 2000 a 2005, geradas pelo modelo, pela Eletrobrás (2001) e por Andrade e Lobão (para o caso residencial):

Tabela 26

Previsões para o consumo residencial (Twh)

\begin{tabular}{cccc}
\hline Ano & Previsão & Eletrobrás & Andrade e Lobão \\
\hline 2000 & 82,7 & 83,5 & 83,2 \\
2001 & 89,1 & 88,7 & 85,4 \\
2002 & 96,0 & 94,5 & 87,5 \\
2003 & 103,5 & 100,6 & 89,4 \\
2004 & 111,5 & 107,0 & 91,4 \\
2005 & 120,2 & 113,7 & 93,3 \\
\hline
\end{tabular}

Tabela 27

Previsões para o consumo comercial (Twh)

\begin{tabular}{ccc}
\hline Ano & Previsão & Eletrobrás \\
\hline 2000 & 45,4 & 46,7 \\
2001 & 47,3 & 49,8 \\
2002 & 49,6 & 53,2 \\
2003 & 52,3 & 56,9 \\
2004 & 55,2 & 60,8 \\
2005 & 58,5 & 64,9 \\
\hline
\end{tabular}


Tabela 28

Previsões para o consumo industrial (Twh)

\begin{tabular}{ccc}
\hline Ano & Previsão & Eletrobrás \\
\hline 2000 & 124,2 & 131,3 \\
2001 & 125,1 & 137,4 \\
2002 & 126,0 & 143,4 \\
2003 & 126,9 & 148,3 \\
2004 & 127,6 & 154,4 \\
2005 & 128,3 & 162,4 \\
\hline
\end{tabular}

Como se pode observar pelas tabelas acima, as previsões geradas pelo modelo resultam em valores menores do que os previstos pela Eletrobrás (2001), sendo a diferença mais expressiva no caso industrial e excetuando o segmento residencial. Neste, as previsões foram superiores (exceto 2000) às previsões tanto da Eletrobrás quanto do trabalho de Andrade e Lobão.

\subsection{Racionamento de energia}

Na primeira metade do ano de 2001, as chuvas se concentraram na região sul do Brasil, resultando num baixo nível de água nos reservatórios localizados nas demais regiões do país. Como a produção de energia elétrica brasileira é basicamente hídrica, como não há interconexão de transmissão de energia elétrica entre os sistemas Sul e Norte e como mesmo no sub-sistema Sul/Sudeste/CentroOeste a interconexão não apresenta mobilidade perfeita entre Sul e Sudeste ou Sul e Centro-Oeste ${ }^{19}$ o abastecimento nacional ficou demasiadamente prejudicado, inviabilizando que os excedentes gerados no Sul pudessem ser aproveitados nas demais regiões do país.

Com isso, foi necessária a implementação, a partir de junho de 2001, de um programa de racionamento de energia elétrica, em que foram incluídas as regiões Sudeste, Nordeste e Centro-Oeste, e os estados do Pará, Tocantins e Maranhão. ${ }^{20}$ Foram definidas metas de consumo, em cada mês, para cada família, unidade comercial ou industrial. Estas metas seriam a média de consumo ocorrida entre os meses de maio e julho de 2000 e valeriam para todos os demais meses subseqüentes

\footnotetext{
${ }^{19}$ Ver parecer $n^{o} 327 /$ SEAE/MF, de 30/09/2002, referente à constituição de um consórcio entre as requerentes (Consórcio Eletrobolt) para construção de uma usina termelétrica, no subsistema Sudeste/Sul/Centro-Oeste.

${ }^{20}$ Estes três estados só aderiram ao racionamento a partir de agosto de 2001 . Ver nota de rodapé 5 .
} 
a partir da implementação do racionamento. ${ }^{21}$

A punição pelo não cumprimento da meta se deu via preço. Isto é, aqueles que ficassem com o consumo aquém da meta ganhariam desconto na tarifa e aqueles que a extrapolassem teriam que pagar uma tarifa mais elevada. Para estes últimos, se a meta fosse extrapolada por três meses consecutivos, haveria corte de energia elétrica.

Esta restrição resultou, provavelmente, em uma quebra estrutural na série de consumo de energia elétrica. Isto é, a partir de junho de 2001, o padrão de consumo de energia elétrica da população brasileira deve ter se alterado. Mesmo assim, as elasticidades encontradas devem continuar refletindo a realidade, e, conseqüentemente, as previsões geradas para o período de 2001 a 2005.

No entanto, como houve grande adesão da população às metas, uma reflexão importante pode ser feita. Neste trabalho, assim como na literatura, as estimações de elasticidades-preço geralmente são baixas, mostrando que o consumidor é pouco sensível à variações no preço de energia elétrica. Desta forma, esperar-se-ia que uma política de racionamento, cuja punição se deva via preço, não seria a mais apropriada entre outras possíveis políticas, pois não traria resultados tão rápidos. Ou seja, esperar-se-ia que para que o racionamento tivesse um efeito relevante na quantidade demanda, o aumento na tarifa, via punição, deveria ser extremamente elevado, o que não foi. Assim, à princípio parece haver uma questão relevante a ser perquerida, sugestão para um segundo trabalho.

\section{Conclusão}

O presente trabalho, de natureza empírica, procurou contribuir para estimações de algumas elasticidades, dentre elas, as elasticidades-renda e preço da demanda por energia elétrica no Brasil, nas três classes: residencial, comercial e industrial.

De forma geral, os dois estudos anteriormente realizados para este país (Modiano (1984) e Andrade e Lobão (1997)) obtiveram resultados um pouco distintos para as elasticidades-preço na classe residencial. O presente trabalho obteve um valor intermediário aos dois, $-0,085$, sendo mais próximo ao de Andrade e Lobão. Já para as demais classes de consumo, apenas Modiano realizou estimações e seus resultados, para as elasticidades-preço, apresentaram valores bem próximos aos deste, que foram: $-0,174$ para o comercial e $-0,545$ para o industrial.

\footnotetext{
${ }^{21}$ Para as classes comercial e residencial, a meta seria $20 \%$ a menos do consumo dos três meses mencionados. Já com relação à classe industrial, o percentual de redução dependeria do setor de atividade da empresa.
} 
No concernente à elasticidade-renda, no caso residencial, o valor encontrado, 0,539, fica entre os obtidos por Modiano e Andrade e Lobão. Já para os casos comercial e industrial, 0,636 e 1,916, respectivamente, não contemplados no trabalho de Andrade e Lobão, os valores obtidos foram superiores aos encontrados em Modiano, mas estão de acordo com a premissa deste autor, a qual diz que não se pode rejeitar a hipótese de que aquela elasticidade seja maior do que um.

Com relação às previsões para os anos de 2000 e 2001, obtidas a partir dos MCEV, estas se mostraram próximas aos valores efetivamente observados, o que indica que o modelo utilizado é adequado. No tocante às previsões para o período de 2002 a 2005, estas podem ter sido prejudicadas pelo racionamento ocorrido no ano de 2001, que pode ter gerado uma quebra estrutural nas séries de consumo de energia elétrica.

Como possíveis extensões do presente trabalho, algumas sugestões podem ser feitas. Primeira, que as estimações das elasticidades de curto prazo para as três classes de consumo poderiam ser realizadas utilizando metodologia semelhante à usada por Braga (2000). ${ }^{22}$ Segunda, que a estimação poderia ser feita pelo mesmo método deste artigo, mas considerando séries mensais. Terceira, poderia ser elaborado outro modelo para o caso industrial, o qual não apresenta os resultados esperados neste trabalho. Quarta, poderia ser analisada a questão de como pode as elasticidades preço serem baixas e a população ter aderido tão bem ao racionamento, dado que a punição se deu via preço.

\section{Referências}

Almeida, D. R. (1983). Política tarifária e financiamento do setor de energia elétrica no Brasil: Estudo e análise da evolução recente. Tese de Mestrado, Coope.

Andrade, T. \& Lobão, W. (1997). Elasticidade-renda e preço da demanda residencial de energia elétrica no Brasil. Texto para discussão n. 489, RJ, IPEA.

Becker, G. (1971). Economic Theory. University of Chicago, 1st edition.

Beenstock, M., Goldin, E., \& Nabot, D. (1999). The demand for electricity in Israel. Energy Economics, 21:168-83.

Bentzen, J. \& Engsted, T. (1993). Short and long-run elasticities in energy demand - a cointegration approach. Energy Economics, 15(1).

\footnotetext{
${ }^{22}$ Para a obtenção das elasticidades-preço e renda de curto e longo prazos a autora utilizou a função de transferência de Box-Jenkins.
} 
Berndt, E. (1991). The Practice of Econometrics: Classic and Contemporary. MIT and National Bureau of Economic Reserch.

Braga, J. (2000). A modelagem da demanda residencial de energia elétrica. Dissertação de mestrado, IE-UFRJ.

Christopoulos, D. K. (2000). The demand for energy in Greek manufacturing. Energy Economics, 22:569-86.

Dickey, D. \& Fuller, W. A. (1979). Distributions of the estimates for autoregressive time series with a unit root. Journal of the American Statistical Association, 74:427-431.

Dickey, D. \& Fuller, W. A. (1981). Likelihood ratio statistics for autoregressive time series with a unit root. Econometrica, 49:1057-72.

Donatos, G. S. \& Mergos, G. J. (1991). Residential demand for electricity: The case of Greece. Energy Economics, 13:41-47.

Eletrobrás (2001). Mercado brasileiro de energia - relatório analítico ciclo 2000.

Enders, W. (1995). Applied Econometric Time Series. John Wiley \& Sons, New York.

Engle, R. F. \& Granger, C. W. J. (1987). Co-integration and error correction: Representation, estimation and testing. Econometrica, 55:251-276.

Hamilton, J. (1994). Time Series Analysis. Princeton University Press.

Hendry, D. F. (1995). Dynamic Econometrics. Oxford University Press, Oxford.

Holanda, F. H. (1985). Microeconomia: Teoria, modelos econométricos e aplicações à economia brasileira. Ipea/Inpes.

Houthakker, H. S. (1951). Some calculations of electricity consumption in great Britain. Journal of the Royal Statistical Society, (114):351-371.

Johansen, S. (1988). Statistical analysis of cointegrating vectors. Journal of economic dynamics and control, 12:231-254.

Johansen, S. (1991). Estimation and hypothesis testing of cointegrating vectors in Gaussian vector autoregressive models. Econometrica, 59:1551-80. 
Johansen, S. \& Juselius, K. (1990). Maximum likelihood estimation and inference on cointegration with application to the demand for money. Oxford Bulletin of Economics and Statistics, 52:169-209.

Leite, A. D. (1997). A Energia Do Brasil. Editora Nova Fronteira.

Lizardo, J. A. (1996). Regulação de monopólios e mercados: Questões básicas. RJ, UFRJ/IE.

Mas-Colell, A., D., W. M., \& Green, J. R. (1995). Microeconomic Theory. Oxford University Press.

Modiano, E. M. (1984). Elasticidade-renda e preço da demanda de energia elétrica no Brasil. Texto para discussão $n^{o} 68$, Departamento de economia - PUC/RJ.

Nogueira, E. M. C. (1996). As recentes mudanças no setor elétrico: Do monopólio à abertura de mercado. Tese de Mestrado FGV/RJ.

Rahbek, A. \& Mosconi, R. (1999). Cointegration rank inference with stationary regressors in VAR models. Econometrics Journal, 2:76-91.

Rigolon, F. (1996). Regulação da infra-estrutura: A experiência recente no Brasil. Rio de Janeiro: BNDES.

Silk, J. I. \& Joutz, F. L. (1997). Short and long-run elasticities in US residential electricity demand. Energy Economics, 19:493-513.

Smith, K. (1980). Estimating the price elasticity of US electricity demand. Energy Economics, 2:81-85.

Westley, G. D. (1984). Electricity demand in a developing country. Review of Economics and statistics.

Westley, G. D. (1989). Commercial electricity demand in a central american economy. Applied Economics, 21.

Wills, J. (1981). Residential demand for electricity. Energy Economics, 3:249-55. 